In the Special Issue on Multicultural Social Justice Leadership Development Guest Editor: Carlos P. Zalaquett, University of South Florida

\title{
Social Justice Counseling and Advocacy: Developing New Leadership Roles and Competencies
}

\author{
Judith A. Lewis \\ Governors State University \\ Manivong J. Ratts \\ Seattle University \\ Derrick A. Paladino \\ Rollins College \\ Rebecca L. Toporek \\ San Francisco State University
}

\begin{abstract}
The fusion of scholarship and activism represents an opportunity to reflect on ways in which counselors and psychologists can begin to address the multilevel context faced by clients and client communities. Counselors and psychologists have embraced, and sometimes resisted, the wide range of roles including that of advocate and activist. This article reflects on a process that engaged workshop participants in examining the American Counseling Association Advocacy Competencies and exploring the possibilities of advocacy on behalf of their own clients. Further, the article presents recommendations for actions developed by participants through application of workshop principles regarding social action in the larger public arena. The workshop was a part of the National Multicultural and Social Justice Leadership Academy in 2010.
\end{abstract}

Keywords. advocacy, social justice; political action; change promotion, leadership development 
Kelman (2010), in a discussion of psychology and social responsibility, suggested that there are two ways in which psychologists can carry out their social responsibilities: via psychology and in psychology. Kelman's conceptualization implies that a psychologist can use his or her work as a vehicle for bringing about social change. It also implies that the psychologist has a responsibility to change the nature of the profession itself, moving individual psychologists and the discipline as a whole toward a fusion of activism with scholarship. These ideas are clearly as relevant to counselors and other helping professionals as they are to psychologists.

The purpose of this article is to propose a fusion of among scholarship, professional practice, advocacy, and leadership and provide recommendations for the application of advocacy in leadership. The content and process of a workshop focusing on developing new leadership roles and competencies given through the National Multicultural and Social Justice Leadership Academy in 2010, provides the basis for our discussion. In this workshop, the authors broadened the concept of fusion, helping participants to perceive and plan for action through a process that led toward this goal. The process began with an introduction to the social justice counseling paradigm, including a review of the American Counseling Association (ACA) Advocacy Competencies and a discussion of social action in the larger public arena. Two interactive exercises led the workshop participants to connect theory to practice exploring the possibilities of advocacy on behalf of their own clients and making recommendations for actions that might take the helping professions in positive new directions. The workshop took place in the context of an American Counseling Association conference where participants largely defined themselves professionally as counselors, counselor educators, or counselors in training. The language used throughout the event focused on counseling practice and the social justice counseling paradigm, but the authors recognize that the counseling profession is not alone in the steady movement toward an emphasis on social justice. The process described, and the content, may help to advance advocacy across disciplines.

Across the helping professions, a social justice perspective represents a shift from traditional, individually-focused models. The history of community psychology, for example, exemplifies a change in worldview from established psychological traditions. "Psychology has traditionally focused on the individual level of analysis...This is a very western view that puts the individual in the foreground over the collective...In contrast, CP is the study of people in context" (Nelson \& Prilleltensky, 2005, p. 5). The vanguard of each of the helping professions has embraced the concept of social justice (Toporek, Gerstein, Fouad, Roysircar, \& Israel, 2006; Sowers \& Rowe, 2006). Within the counseling profession, the cutting edge is exemplified by the social justice counseling paradigm.

\section{The Social Justice Counseling Paradigm}

Counselors who believe in the possibility of a humane world incorporate a social justice perspective into their work with clients. The social justice counseling paradigm "uses social advocacy and activism as a means to address inequitable social, political, and economic conditions that impede the academic, career, and personal/social development of individuals, families, and communities" (Ratts, 2009, p. 160). Social justice counselors contend that human development issues cannot be understood simply by assessing a client's affective, behavioral, or 
cognitive development or by requiring that change come exclusively from the client. Instead, counselors need to view client problems more contextually and use advocacy to remove oppressive environmental barriers.

According to Adams, Bell, and Griffin (2007), achieving social justice is both a goal and a process. The goal of social justice counseling is to ensure that every individual has the opportunity to reach her or his academic, career, and personal/social potential free from unnecessary barriers. This perspective is rooted in the belief that every individual has a right to a quality education, to healthcare services, and to employment opportunities regardless of race, ethnicity, sex, sexual orientation, gender identity, gender expression, economic status, and creed, to list a few. The process for achieving social justice should be one that involves the client throughout the counseling process. Counseling should be a collaborative experience where clients are a participatory part of the process. Clients should have input in the direction of the therapeutic process and they should be equipped with the awareness, knowledge and skills needed to navigate their world successfully.

The social justice counseling paradigm brings many benefits to the helping professions. A counseling paradigm rooted in social justice provides a theoretical framework for understanding the debilitating impact oppression has on clients' ability to reach their potential. The paradigm encourages counselors to develop a more balanced perspective between individuals and their environment and expands the repertoire of skills counselors have at their disposal. Rather than being limited to working in the traditional office environment, counselors can also work in the settings that contribute to client stress. As a theory unto itself, the social justice counseling paradigm has altered how client problems are conceptualized, has revolutionized the counselor role and identity, and has led to avant-garde counseling approaches (Ratts, 2009). The shift in the counseling paradigm is significant because counselors cannot continue to do the same things if they intend a different outcome. Lorde (1984) stated, "the master's tools will never dismantle the master's house" (p. 110). In other words, we cannot rely on theories and ways of helping to dismantle the status quo if the theories we use were built to maintain the social order. Unfortunately, many traditional counseling and psychological theories have been complicit in maintaining the status quo of White supremacy and patriarchy (Prilleltensky, 1994). Now, more counselors recognize the need for a new counseling paradigm that will heed to clients' needs, and as a byproduct, revolutionize the counseling profession. One of the roles and functions recognized by this paradigm is that of client advocate. This role requires using the skills and knowledge of counselors and psychologists to facilitate change in the environment.

\section{The ACA Advocacy Competencies}

In recognition of the need for counselors to acknowledge and play critical roles in addressing barriers faced by clients, ACA adopted a set of guidelines to assist in this process (Lewis, Arnold, House \& Toporek, 2002). The ACA Advocacy Competencies integrated the foundations provided by literature in multicultural counseling (e.g., Sue, Arredondo \& McDavis, 1992) and community counseling (e.g., Lewis, Lewis, Daniels \& D'Andrea, 1998) and provided a framework through which counselors could identify the various levels of intervention that might be appropriate given client situations. We will provide a brief overview of the model as context for the exercise and participant experience, however, a more extensive discussion of the ACA Advocacy Competencies model can be found in a special issue of the Journal for Counseling and 
Development (Toporek, Lewis \& Crethar, 2009) as well as in an edited handbook devoted to the ACA Advocacy Competencies (Ratts, Toporek \& Lewis, 2010).

The ACA Advocacy Competencies model organizes advocacy into two dimensions. The first dimension identifies the extent of involvement of client or community in the advocacy process; in other words, is advocacy taken with the client or on behalf of the client? The second dimension addresses the level of intervention: individual, systems, and societal level. The resulting domains describe six different forms of advocacy that counselors may be involved in depending on the needs of the situation. Often, several forms of advocacy may be necessary and cultural competence and awareness is essential regardless of the type of advocacy.

At the individual level, the counselor works with the client or student toward Empowerment. Empowerment may involve facilitating the process of naming the barrier or oppression and working together to develop strategies that the client may use to address the barrier. Sometimes the counselor may facilitate the development of self-advocacy skills or helping the client locate resources that may help address the contextual problems. It is critical that the counselor have adequate training and understanding of the cultural complexities that may be involved for the client within and outside his or her community. There are times and situations in which the counselor has access or resources that cannot be transferred to the client. For example, by virtue of their position, counselors tend to receive more credibility and access within their own or related institutions. In other cases, the cognitive or language skill level of the client may make it difficult for the client to understand or advocate for themselves in some circles. Similarly, clients or students may face serious repercussions when self-advocating without support of someone who is has institutional power. In these cases, it would be appropriate for the counselor to advocate on behalf of the client or student. The model calls this Client or Student Advocacy.

At a systems level, the ACA Advocacy Competencies model identifies Community Collaboration as the efforts of counselors to work with a community or school to address some oppression or barrier facing the community. This type of advocacy is similar to empowerment but is working at a group level using counselors' skills in group facilitation, prevention, communication, consultation and collaboration. In this way, counselors may help a group to define the problems facing the community or school and then facilitate the group in identifying and planning action to address these problems. Systems Advocacy identifies advocacy efforts the counselor makes on behalf of a school or community. There may be situations where client groups may fear of repercussions and hence may not raise issues at a systems level. In other cases, there may not be a cohesive group that identifies a problem, but the counselor sees patterns across a number of clients or students. For example, over the course of a year or two a counselor noted that a number of students from a particular ethnic background came to her describing incidents of discrimination in a specific college department. The students did not know that others experienced similar issues and, although some pursued due process, many did not and left the college instead. When counselors see these patterns within their own institutions, advocacy on behalf of those communities would be not only appropriate, but ethically imperative.

When a counselor works in conjunction with a client community on a societal level, the ACA Advocacy Competencies model identifies this as Public Information. Public information describes the work that a counselor, or group of counselors, may do in conjunction with a community to raise awareness about an issue. For example, in a community where there are high rates of 
micro-aggressions against a particular marginalized group, the counselor may work with members of the group to identify ways to amplify their voice and presence in the community in a way that would inform the community about the issues as well as build relationships and allies within the community. Finally, when a counselor advocates on behalf of client communities at a societal level, this is termed, Social or Political Advocacy. In this form of advocacy, the counselor directly works with policy makers and legislators to address issues that negatively affect client groups. This often takes place concurrently with other forms of advocacy. The counselor's ability to recognize issues facing a population comes from her or his involvement with members of that community and the advocacy should be informed by those community members. Counselors are in a unique position in that their direct client experience and stories can be blended with statistics and information to create compelling arguments for policy change. Of course ethically, any stories shared must protect the confidentiality of the clients unless specifically directed by the client. As an example, a group of counselors and psychologists met with a legislative office regarding the need for more training for bilingual mental health services. They presented statistics about mental health needs and disparities as well as the economic impact of mental health problems on a community. The legislative staff member fastidiously recorded much of the information provided. A pivotal point was reached when one of the counselors shared a letter that one of her clients had written for this event. The staff member was emotionally moved and firmly stated that she would make sure that this issue was given attention.

Several important aspects of the ACA Advocacy Competencies model are worth repeating here. First, many situations call for multiple forms of advocacy concurrently. Second, advocacy should reflect the clients' needs and be informed by clients rather than the counselor determining what the client needs. Similarly, it is not the counselor's job to "save" the client or client groups. Rather, the counselor facilitates the client in gaining more skill and power. Sometimes, in addition to this, the counselor may independently need to advocate. Third, multicultural competence and relevance is of utmost importance. Fourth, interdisciplinary and cross organizational alliances are often necessary in order to advocate effectively. Fifth, counselors have significant skill and training to facilitate their advocacy efforts including group dynamics, prevention, communication, human behavior and development, and systems knowledge. However, there are areas in which more training would be useful depending on the counselor's strengths and experience; for example, training in legislative advocacy (Lee, 2009) or translation of ethical issues when working with communities (Toporek \& Williams, 2006).

\section{Social/Political Action}

Advocacy is not an "add-on" that is separate from the counselor's work with clients and students. Advocacy is, instead, a natural outgrowth of the counselor's empathy and experience.

In the past, most community organizations and social/political advocacy groups functioned in a world apart from individuals who identified themselves as members of the helping professions. Now, however, the separate worlds of counseling and macrolevel advocacy have begun to merge. Community counselors no longer turn their backs on the need for social/political action because they realize that this work is a natural continuation of the counseling process. Helping individuals and dealing with the social/political systems that affect them are two aspects of the same task. (Lewis, Lewis, Daniels, \& D'Andrea, 2011, p. 206) 
Lewis, Toporek, and Ratts (2010) suggest that counselors can find their way toward "a seamless connection between what they do in the counseling office and what they do in the Capitol Building" (p. 241). The best way to make this bond a reality is to begin with the client. The idea of beginning with the client suggests that experiences with clients can help counselors choose the most important issues and the best allies for social/political advocacy. Cohen, de la Vega, and Watson (2001) suggest that "effective social movements are built by well-rounded teams of storytellers, organizers, and 'experts' alike" (p. 29). Counselors, almost by definition, have stories to tell and those stories lead the way toward social justice advocacy.

\section{Group Activity: Stories to Tell}

Counselors advocate for their clients constantly, but are not always aware of their strengths in this area. Sometimes these behaviors are second-nature, anchored in the altruism possessed by mental health professionals. For example, one of the authors remembers spending hours calling different inpatient sites trying to find a bed for one of his clients. He was informed that there were no open beds in the state and his client did not "technically" match the requirements for this level of care. Through persistence and calls to community contacts, this client was finally offered a spot in an inpatient agency. At the time, the author labeled this as simply knowing what the client needed and caring about him, not as advocacy - even though it actually reflects the principles of advocacy.

Counselors may find that they already possess strong leadership and advocacy skills as they work with clients. One goal of the workshop described in this article was to develop new leadership roles in social justice counseling and advocacy. One of our hopes, as facilitators, was to illuminate these skills and strategies in a community forum. At this part of the workshop, we aimed at tapping into the micro-level work participants were already involved with. The goal was to increase the participants' awareness of their work, reinforce this level of client care and facilitate movement towards a blueprint that operationalizes future social justice and advocacy at the micro and, later in the workshop, macro level.

In the workshop, presenters asked participants to reflect on their advocacy and social justice experiences with specific clients. Participants were asked to break into small groups, particularly with individuals who were not their own current colleagues. They were provided with discussion questions and asked to take notes on their responses. At the conclusion of this discussion the presenters proceeded to process the small group work in the larger group. Participants were given the following prompts:

1) Talk about your experiences.

a. In what ways have you been successful with advocacy with a specific client?

b. What roadblocks did you traverse?

2) As you look at what has worked for you in advocacy and social justice counseling, identify strategies and skills that helped you advocate for individual clients.

Eight small groups were formed and reported on the main areas above: Experiences, Roadblocks and Barriers, and Strategies and Skills. 


\section{Experiences}

Perhaps the most interesting aspect of this exercise was that even counselors who had not viewed themselves as competent advocates did have examples to share. All of the participants, including students, could give real-life examples of times when they had spoken up on behalf of less powerful others. Although this workshop might have been their first introduction to the concept of social justice counseling and advocacy, they could readily see the fit with their own experiences.

The examples shared were quite diverse and demonstrated the wide array of possibilities in micro-level advocacy. Participants were able to advocate in areas spanning from single-parent families in an American suburb to refugees Burundi, Africa. Experiences with children and youth were especially prevalent. One participant working with a teen boy living with stuttering was able to advocate successfully for speech therapy. This participant found that a new device could assist this teen, but insurance didn't cover it. After realizing that traditional methods didn't work, the counselor was able to arrange for the donation of the device and the client benefited greatly. Another example involved a six-year-old boy with speech issues in a school counseling setting. The counselor was able to assist the client by shifting perceptions and attitudes through education on diversity, working with the teacher, and using a backdoor approach including connecting with others and creating allies.

\section{Roadblocks and Barriers}

Although the participants in the workshop expressed multiple examples of roadblocks that could impede advocacy and social justice, they showed active energy and passion. Examples of nonsuccessful advocacy efforts reported by the participants are important to highlight. Participants shared similar struggles as they discussed roadblocks to advocacy and social justice. Among the most common barriers were (a) insurance and funding issues, (b) lack of community support and resources, (c) unexpected resistance, (d) difficult in building collaborative networks, (e) cultural and language biases, and (f) the counselor's own limited training in social justice advocacy.

These recollections of struggles were shared by many. It is the collective awareness of roadblocks and shared struggles that can bring mental health professionals together to discover new ways to increase levels of success. The advocacy and social justice road does not have to be traveled alone. Working alone in advocacy can make these barriers appear quite insurmountable; however, through the activity the authors discovered that participants offered many solutions as a group. When mental health professionals make connections and collaborate, success is possible.

\section{Strategies and Skills}

Participants shared both experienced and proposed strategies for advocacy and social justice at the micro-level. The strategies identified by participants appeared best organized into three main areas community and colleagues, client, and person-as-counselor. 
Community and colleagues. This theme reflected the ways in which participants found strength in working with others to advocate for a common purpose. Participants identified who they collaborated with as well as specific actions that took place within the context of these partnerships. These included:

- Collaboration with other professionals (interdisciplinary)

- Sharing resources and information

- Advocating for other services

- Educating/information giving regarding cultures to everyone in the environment or community

- Connecting with outside systems-collaboration

- Specific alliances-backdoor approaches

- Making advocacy letters to legislatures personal and contacting local legislatures/ lobby to work your way up

- Networking (technology, social networking sites)

Client. This theme summarized the ways in which participants worked with clients within the context of advocacy. Most of these examples reflected approaches or intentions of the counselor. Specifically, participants noted the following:

- Understanding the client's culture

- Looking at, identifying, and celebrating strengths

- Empowering your clients

- Education/support-empowerment/education

- Visiting clients' houses-seeing/experiencing the physical living environmentbecoming immersed in context

- Being in environment to educate clients about their rights and things they can do

- Gaining trust and respect of the client

- Teaching assertiveness

- Educating clients of their rights-how to obtain them

Person-As-Counselor. This theme focused on comments made by participants regarding the role of the self in acting as an advocate. Some of the participants identified personal challenges and others highlighted the ways in which professional training and identity support advocacy efforts. The range of discussion points can be seen here:

- Taking the risk to be an advocate

- Acknowledging that we have more in common than differences

- Utilizing title of role as counselor

- Using the power for good

- Sharing personal experiences with your clients

- Becoming an educator

- Knowing and identifying with our clients

- Understanding the needs of the population from the perspective of the population you are working with

- Organization as self-advocacy goals

- More community involvement

- Modeling self-advocacy strategies 
The themes expressed by participants rose through shared stories, experiences, and strategies with each other within the context of a small group activity. As facilitators, we observed the power of these small group discussions and noted that, in the large group discussions that followed, participants created a collegial environment and reported having learned new approaches to advocacy and social justice. For example, a participant noted that "modeling selfadvocacy strategies" occurred in the process. Throughout this activity, we observed participants working at the micro-level, looking at themselves and reporting an increase in their awareness regarding advocacy and social justice.

\section{Group Activity: Social/Political Action}

As described above, early in the workshop, the presenters asked participants to share their own stories regarding their work with individual clients and students. As the program moved toward a discussion of social/political action, the workshop participants were asked to revisit those stories and make recommendations for more broad-based actions. In identifying pressing issues for public advocacy, the participants were asked to do the following:

- Start with a client and consider the ways in which this client's life could be improved if the social/economic/political environment were to change.

- List ideas for social/economic/political changes that should be accomplished in the larger public arena, with particular focus on the role of the counselor and the counseling profession.

Because the first experiential activity had involved starting with the client, the intent was that participants would be able to move seamlessly toward the larger public arena.

The participants' action recommendations were shared in the context of the large group and included the following:

1. To use our role as counselors to carry out social action (social justice via counseling):

- Advocate on behalf of ALL marginalized groups-not just the obvious ones. (The example used was deaf and hard-of-hearing clients.)

- Advocate on behalf of returning military. (As many as $50 \%$ of returning military are unemployed. Counselors should advocate on behalf of military families, especially regarding employment.)

- In difficult economic times, educate corporate America about the impact of their decisions on workers.

- Carry out advocacy on behalf of workers.

2. To bring about change in the counseling profession as a whole (social justice in counseling):

- Ensure that all committees of counseling organizations have a social justice charge. 
- Ensure that advocacy regarding public policy and legislation is included in every counseling student's training. As part of their training, all students should be able to develop relationships with legislators.

Some of the participants' action recommendations grew directly from their exploration of client issues. It is particularly interesting, however, that the participants also recommended actions that help to move social/political advocacy to the center of the counseling profession. For example, participants recommended that professional associations, such as the American Counseling Association, should operationalize social justice concepts by insisting that all committees within the organization are charged with emphasizing social justice. They also recommended that advocacy should play a central role in every student's preparation for practice. These ideas reflect an internalization of a commitment toward social justice counseling.

\section{Conclusion}

The format of this workshop appeared successful in generating an understanding of, and appreciation for, social justice counseling and advocacy among the participants, many of whom had been unfamiliar with these concepts in the past. By reviewing the social justice counseling paradigm and the ACA Advocacy Competencies, facilitators hoped to lay the groundwork for the heart of the program, which involved active participation and brainstorming. In the small-group activity, participants talked about their own personal and professional experiences. Through the discussion with others, they were exposed to these experiences from a different perspective. New perspectives expand counselors' ability to identify necessary action as well as understand how these actions relate to, and are appropriate for, professional counselors. Not only the participants but the workshop leaders as well developed clearer views of the fusion among scholarship, social justice counseling, advocacy, and leadership. Our intent in describing the workshop process, as well as strategies derived from the group activities, is to increase dialogue regarding challenges and positive approaches that can help further the implementation of advocacy within counseling and psychology. In particular, the future leaders in the counseling and psychology fields will need skills and the strength to advocate for social justice.

Contact information/Correspondence:

Judith A. Lewis

Email: Judithalewis@sbcglobal.net

Judith A. Lewis, Ph.D., Governors State University, Manivong J. Ratts, Ph.D., Seattle University, Derrick A. Paladino, Ph.D., Rollins College; and Rebecca L. Toporek, Ph.D., San Francisco State University. 


\section{References}

Adams, M., Bell, L. A., \& Griffin, P. (Eds.). (2007). Teaching for diversity and social justice (2nd ed.). New York: Routledge.

Cohen, D., de la Vega, R., \& Watson, G. (2001). Advocacy for social justice: A global action and reflection guide. Bloomfield, CT: Kumarian Press.

Kelman, H. (2010, July 17). Becoming a socially responsible psychologist. Presented to the annual conference of Psychologists for Social Responsibility, Boston, MA.

Lee, C., \& Rodgers, R. (2009). Counselor advocacy: Affecting systemic change in the public arena. Journal of Counseling \& Development, 87, 284-287. Retrieved from PsycINFO database.

Lewis, J. A., Arnold, M. S., House, R., \& Toporek, R.L. (2002). ACA Advocacy Competencies. Advocacy Task Force, American Counseling Association. Retrieved September 13, 2008, from http://www.counseling.org/resources/html.

Lewis, J. A., Lewis, M. D., Daniels, J. A., \& D'Andrea, M. J. (1998). Community counseling: Empowerment strategies for a diverse society (2nd ed.), Pacific Grove, CA: Brooks/Cole Publishing Company.

Lewis, J. A., Lewis, M. D., Daniels, J. A., \& D'Andrea, M. J. (2011). Community counseling: $A$ multicultural social justice perspective ( $4^{\text {th }}$ ed.). Belmont, CA: Brooks/Cole Cengage.

Lewis, J. A., Toporek, R. L., \& Ratts, M. J. (2010). Advocacy and social justice: Entering the mainstream of the counseling profession. In M. J. Ratts, R. L. Toporek, \& J. A. Lewis (Eds.), ACA Advocacy Competencies: A social justice framework for counselors (pp. 239-244). Alexandria, VA: American Counseling Association.

Lorde, A. (1984). The master's tools will never dismantle the master's house. In A. Lorde (Ed.), Sister outsider: Essays and speeches (pp. 110-113). Santa Cruz: The Crossing Press.

Nelson, G., \& Prilleltensky, I. (2005). Community psychology: In pursuit of liberation and wellbeing. New York: Palgrave MacMillan.

Prilleltensky, I. (1994). The morals and politics of psychology: Psychological discourse and the status quo. New York: State University of New York Press.

Ratts, M. J. (2009). Social justice counseling: Toward the development of a "fifth force" among counseling paradigms. Journal of Humanistic Counseling, Education, and Development, $48,160-172$.

Sowers, K. M., \& Rowe, W. S. (2006). Social work practice and social justice: From local to global perspectives. Belmont, CA: Cengage Learning.

Sue, D., Arredondo, P., \& McDavis, R. (1992). Multicultural counseling competencies and standards: A call to the profession. Journal of Counseling \& Development, 70, 477-486. 
Toporek, R. L., Gerstein, L. H., Fouad, N. A., Roysircar, G., \& Israel, T. (2006). Handbook for social justice in counseling psychology: Leadership, vision and action. Thousand Oaks, CA: Sage.

Toporek, R. L., Lewis, J. \& Crethar, H. C. (2009). Promoting systemic change through the Advocacy Competencies. Special Section on ACA Advocacy Competencies. Journal of Counseling and Development, 87, 260-268.

Toporek, R.L., \& Williams, R.A. (2006). Ethics and professional issues related to the practice of social justice in counseling psychology. In R.L. Toporek, L.H. Gerstein, N.A. Fouad, G.S. Roysircar, \& T. Israel (Eds.) Handbook for social justice in counseling psychology: Leadership, vision, \& action (pp. 17-34). Thousand Oaks, CA: Sage.

Vera, E. M., \& Speight, S. L. (2003). Multicultural competence, social justice, and counseling psychology: Expanding our roles. The Counseling Psychologist, 31(3), 253-272. doi: $10.1177 / 0011000003031003001$. 